\title{
EVALUASI PROSEDUR AUDIT DALAM RANGKA PEMENUHAN TUJUAN AUDIT ATAS PIUTANG USAHA
}

\author{
Andhita Yukihana Rahmayanti ${ }^{1}$ \\ Birawani Dwi Anggraeni ${ }^{2}$ \\ Laboratorium Akuntansi Program Vokasi Universitas Indonesia, a.yukihana@ui.edu,birawani@yahoo.co.uk
}

\author{
Diterima : 1 April 2015
}

Layak Terbit : 12 Mei 2015

\begin{abstract}
Abstrak
Penelitian ini menekankan pada sejauh mana prosedur audit yang dilakukan atas piutang usaha perusahaan-perusahaan non publik telah memenuhi tujuan auditnya, baik tujuan audit terkait saldo ataupun tujuan audit terkait penyajian dan pengungkapan. Auditor melakukan prosedur audit termasuk pengujian pengendalian dan pengujian terperinci atas saldo piutang usaha, untuk memperoleh keyakinan bahwa tujuan auditnya telah terpenuhi sehingga informasi dan angka-angka yang ada dalam penyajian dan pengungkapan sesuai dengan standar yang berlaku umum di Indonesia. Metode penelitian yang digunakan adalah metode deskriptif yang menganalisa data-data berupa kertas kerja auditor yang berisi prosedur audit yang dilakukan oleh auditor. Hasil penelitian menunjukkan bahwa belum semua tujuan audit terpenuhi karena belum semua prosedur audit dilakukan oleh auditor. Hal ini mempunyai implikasi yang signifikan terhadap penyajian piutang usaha dalam laporan keuangan yang tidak sesuai dengan standar akuntansinya. Hasil penelitian ini diharapkan dapat memberikan kontribusi ilmu audit.
\end{abstract}

Kata Kunci: piutang usaha, prosedur audit, tujuan audit

\begin{abstract}
This study emphasizes the fulfillness of the audit objectives with performed by evaluating the audit procedures on accounts receivable of non-public company, both related to the audit objectives of detailed balance and the audit objectives of presentation and disclosure. Auditors perform audit procedures include tests of controls and test of detailed balance on accounts receivable account, to reach audit assurances that the audit objectives have been met so that the information and figures included in the presentation and disclosure in accordance with general acceptance standard in Indonesia. This study using the descriptive method which analyzes working papers of auditors that contains the audit procedures performed by the auditor. This study show that not all the audit objectives are met because the audit procedures are not all performed by the auditor. This has significant implications for the presentation of accounts receivable in the financial statements which are not in accordance with the accounting standards. Results of this study are expected to contribute knowledge of audit science.
\end{abstract}

Keywords: account receivable, audit procedures, audit objectives

\section{PENDAHULUAN}

Perusahaan, baik perusahaan publik dan perusahaan non publik, diharapkan mengeluarkan laporan keuangan setiap tahunnya guna dapat memberikan informasi keuangan yang bermanfaat bagi pihak internal dan eksternal. Walaupun untuk laporan keuangan perusahaan-perusahaan non publik tidak diwajibkan diaudit, namun untuk tujuan tertentu, laporan keuangan yang dikeluarkan oleh perusahaan diwajibkan untuk diaudit oleh Kantor Akuntan Publik (KAP). Auditor di KAP melakukan audit atas laporan keuangan berdasarkan sampling yang dinilai tingkat risiko dan tingkar materialitasnya sesuai dengan professional judgement dari auditor tersebut. Salah satu akun yang paling penting dalam laporan keuangan yang dapat mempengaruhi 
keberlangsungan hidup perusahaan di masa yang akan datang adalah piutang usaha. Auditor perlu melakukan prosedur audit termasuk pengujian pengendalian (test of control) dan pengujian terperinci atas saldo (test of detailed balance) piutang usaha, untuk memperoleh tingkat keyakinan (reasonable assurance) bahwa tujuan audit atas akun tersebut telah terpenuhi sehingga informasi dan angka-angka yang ada dalam penyajian dan pengungkapan laporan keuangan sesuai dengan standar yang berlaku umum di Indonesia. Oleh karena itu, penelitian ini dilakukan untuk melihat apakah prosedur audit yang dilakukan oleh auditor telah memenuhi tujuan audit yang seharusnya.

\section{METODE}

Metode yang dipakai dalam penelitian ini adalah metode deskriptif, yaitu dengan melihat kertas kerja auditor dan melakukan rekapitulasi prosedur audit yang telah dilakukan oleh auditor pada saat melakukan audit laporan keuangan di perusahaanperusahaan klien yang non publik. Penelitian ini dilakukan terhadap 21 perusahaan non publik yang diaudit oleh KAP pada periode 2013-2015 untuk tahun buku laporan keuangan yang diaudit 2012-2014. Berikut perincian jumlah perusahaan klien KAP yang dijadikan sebagai obyek penelitian:

Tabel 1. Data sampel penelitian

\begin{tabular}{ccc}
\hline \multirow{2}{*}{ No } & \multicolumn{2}{c}{ Data Perusahaan yang diaudit } \\
\cline { 2 - 3 } & $\begin{array}{c}\text { Tahun Buku } \\
\text { Laporan Keuangan }\end{array}$ & Jumlah perusahaan \\
\hline 1. & 2012 & 2 \\
\hline 2. & 2013 & 4 \\
\hline 3. & 2014 & 15 \\
\hline & Total & 21
\end{tabular}

Kertas kerja yang dikumpulkan dari beberapa staf auditor di KAP yang berbeda dan melakukan wawacara terhadap staf tersebut guna menganalisa dengan rinci apa yang telah dilakukan auditor dalam melakukan audit laporan keuangan tersebut. Untuk mengikuti etika profesi, dalam hal ini kerahasiaan, nama
KAP dan perusahaan yang diaudit tidak dapat disebutkan. Pembatasan masalah penelitian hanya sebatas audit atas akun piutang usaha sehingga kertas kerja yang disampling meliputi kertas kerja audit khusus akun piutang usaha. Rincian nilai piutang usaha yang diaudit memiliki rentang nilai sebagai berikut:

Tabel 2. Data Rentang Nilai Piutang Usaha yang diaudit

\begin{tabular}{ccc}
\hline \multirow{2}{*}{ No } & \multicolumn{2}{c}{ Data Perusahaan yang diaudit } \\
\cline { 2 - 3 } & $\begin{array}{c}\text { Rentang Nilai } \\
\text { Piutang Usaha }\end{array}$ & Jumlah perusahaan \\
\hline 1. & $1-10$ Milyar & 7 \\
\hline 2. & $10-20$ Milyar & 4 \\
\hline 3. & Lebih dari 20 Milyar & 10 \\
\hline & Total & 21 \\
\hline
\end{tabular}

Prosedur audit, bukti audit dan tujuan audit ditabulasi untuk dilakukan analisa terhadap pemenuhannya. Setiap prosedur audit dibandingkan dan dianalisa untuk dilihat apakah sudah memenuhi tujuan audit pengendalian internal dan tujuan audit penyajian dan pengungkapannya.

\section{HASIL DAN PEMBAHASAN}

Penelitian ini dilakukan untuk melihat sejauh mana tujuan audit terpenuhi dengan mengevaluasi prosedur audit atas piutang usaha yang dilakukan auditor pada perusahaan non publik, dan untuk memperoleh keyakinan atas informasi keuangan yang ada dalam penyajian dan pengungkapan sudah sesuai dengan standar yang berlaku umum di Indonesia sesuai dengan tujuan auditnya.

Adapun tujuan audit yang harus dicapai menurut Arens (2014) untuk akun piutang usaha adalah sebagai berikut:

1. Piutang usaha pada neraca saldo menurut umur cocok dengan jumlah pada file master dan jumlah total telah ditambahkan dengan tepat dan cocok dengan buku besar (detail tie-in),

2. Piutang usaha yang dicatat adalah ada (existence), 
3. Piutang usaha yang ada telah dimasukkan semuanya (completeness),

4. Piutang usaha secara mekanis adalah akurat (accuracy),

5. Piutang usaha diklasifikasikan dengan tepat (classification),

6. Piutang usaha dicatat dalam periode yang sesuai (cut off),

7. Piutang usaha dinilai dengan memadai pada nilai yang dapat direalisir (realizable value),

8. Piutang usaha benar-benar sah dimiliki klien (rights),

9. Penyajian dan pengungkapan piutang usaha adalah memadai (presentation $\mathcal{E}^{\circ}$ disclosure).

Biasanya KAP akan melakukan verifikasi atas laporan keuangan dan pengendalian internal melalui serangkaian prosedur audit. Berdasarkan penelitian Boynton et al (2002, p.209) mengatakan prosedur audit adalah metode atau teknik auditor dalam rangka melakukan asesmen dan pengumpulan data, kecukupan serta kompetensi bukti audit. Pada penelitian Souza (1999,p.2) mengatakan bahwa suatu akun akan benar dan pengendalian internal yang baik diperoleh melalui kualitas dan kredibilitas laporan, merupakan langkah yang jelas bagi perusahaan dalam menjalankan bisnis. Penelitian yang dilakukan oleh Santi (1998,p.88) mengatakan bahwa uji kepatuhan sebagai set pengujian prosedur audit yang dirancang untuk mengkonfirmasi terkait fungsi pengendalian internal perusahaan dimana auditor akan menentukan fase audit berikutnya agar audit berjalan efektif. Menurut Guy, Alderman, dan Winter (2002:180) pada penelitiannya menjelaskan bahwa program audit mencakup daftar langkah-langkah pengumpulan bukti yang akan digunakan dalam audit. Agar suatu bukti berguna bagi auditor, maka bukti tersebut harus memiliki empat karakteristik yaitu relevan, bebas dari bias, obyektivitas dan persuasif atau meyakinkan melalui enam jenis bukti audit yakni bukti fisik, pernyataan dari pihak ketiga, bukti matematis, dokumentasi, pernyataan dari personel klien dan keterkaitan data.

Adapun prosedur audit yang dievaluasi adalah prosedur audit menurut Sukrisno Agoes (2014) dengan perincian sebagai berikut:

1. Pahami dan evaluasi pengendalian internal atas piutang dan transaksi penjualan, piutang dan penerimaan kas;

2. Buat Top Schedule dan Supporting Schedule Piutang per tanggal neraca;

3. Minta aging schedule dari piutang usaha per tanggal neraca antara nama pelanggan (customer), saldo piutang, umur piutang dan subsequent;

4. Periksa mathematical accuracy dan check individual balance ke subledger, kemudian totalnya ke general ledger;

5. Test check umur piutang dari beberapa customer ke subledger piutang dan sales invoice;

6. Kirimkan konfirmasi piutang:

a. Tentukan dan tuliskan dasar pemilihan pelanggan yang akan dikirimi surat konfirmasi.

b. Tentukan apakah akan digunakan konfirmasi positif atau negatif.

c. Cantumkan nomor konfirmasi baik di schedule piutang maupun di surat konfirmasi.

d. Jawaban konfirmasi yang berbeda harus diberitahukan kepada klien untuk dicari perbedaannya.

e. Buat ikhtisar / summary dari hasil konfirmasi.

7. Periksa subsequent collections dengan memeriksa buku kas dan bukti penerimaan kas untuk periode sesudah tanggal neraca sampai mendekati tanggal penyelesaian pemeriksaan lapangan (audit field work). Perhatikan bahwa yang dicatat sebagai subsequent collections hanyalah yang berhubungan dengan penjualan dari periode yang sedang diperiksa;

8. Periksa apakah ada wesel tagih (notes receivable) yang didiskontokan untuk mengetahui kemungkinan adanya contingent liability; 
9. Periksa dasar penentuan allowance for bad debts dan periksa apakah jumlah yang disediakan oleh klien sudah cukup, dalam arti tidak terlalu besar dan tidak terlalu kecil;

10. Test sales cut off dengan jalan memeriksa sales invoice, credit note dan lain-lain, lebih kurang 2 (dua) minggu sebelum dan sesudah tanggal neraca. Periksa apakah barang-barang yang dijual melalui invoice sebelum tanggal neraca. Perikasa apakah barang-barang yang dijual melalui invoice sebelum tanggal neraca, sudah dikirim per tanggal neraca. Kalau belum dikirim cari tahu alasannya. Periksa juga apakah ada faktur penjualan dari tahun yang diperiksa, yang dibatalkan dalam periode berikutnya;

11. Periksa notulen rapat, surat perjanjian, jawaban konfirmasi bank dan corespondence file untuk mengetahui apakah ada piutang yang dijadikan sebagai jaminan;

12. Periksa apakah penyajian piutang di neraca dilakukan sesuai dengan standar akuntansi keuangan di Indonesia.

Prosedur audit yang dilakukan oleh setiap KAP akan berbeda tergantung kepada pertimbangan tingkat materialitas dan professional judgement dari KAP tersebut untuk melakukan penilaian terhadap kewajaran suatu laporan keuangan. Pada tahap awal, KAP melakukan prosedur memahami dan mengevaluasi pengendalian internal atas transaksi penjualan, piutang dan penerimaan kas. Hal ini dilakukan untuk mengidentifikasi risiko pengendalian dan risiko audit yang ada di dalam perusahaan. Semakin tinggi pengendalian internal perusahaan, semakin rendah tingkat risiko pengendaliannya.

Dari 21 data kertas kerja audit yang dievaluasi, berikut data evaluasi prosedur audit yang dilakukan oleh penulis:

Tabel 3. Evaluasi Prosedur Audit

\begin{tabular}{cc}
\hline $\begin{array}{c}\text { Nomor } \\
\text { Prosedur } \\
\text { Audit }\end{array}$ & $\begin{array}{c}\text { Persentase } \\
\text { dilakukan } \\
\text { terhadap 21 } \\
\text { perusahaan klien }\end{array}$ \\
\hline 1. & $100 \%$ \\
\hline
\end{tabular}

\begin{tabular}{|c|c|}
\hline $\begin{array}{c}\text { Nomor } \\
\text { Prosedur } \\
\text { Audit }\end{array}$ & $\begin{array}{c}\text { Persentase } \\
\text { dilakukan } \\
\text { terhadap } 21 \\
\text { perusahaan klien }\end{array}$ \\
\hline 2. & $90 \%$ \\
\hline 3. & $81 \%$ \\
\hline 4. & $100 \%$ \\
\hline 5. & $76 \%$ \\
\hline 6.a. & $100 \%$ \\
\hline 6.b. & $95 \%$ \\
\hline 6.c. & $24 \%$ \\
\hline 6.d. & $95 \%$ \\
\hline 6.e. & $95 \%$ \\
\hline 7. & $95 \%$ \\
\hline 8. & $10 \%$ \\
\hline 9. & $76 \%$ \\
\hline 10. & $90 \%$ \\
\hline 11. & $0 \%$ \\
\hline 12. & $100 \%$ \\
\hline
\end{tabular}

Dari tabel 3 dapat dilihat, prosedur audit yang telah dilakukan melebihi $80 \%$ dari 21 perusahaan tidak dilakukan evaluasi lebih lanjut karena dianggap auditor sudah melakukan sesuai dengan seharusnya. Pengevaluasi prosedur audit hanya bagian yang seharusnya tidak berdiri sendiri. Pengevaluasian terhadap prosedur audit harus dikaitkan dengan pemenuhan tujuan audit yang harus dicapai saat melakukan audit atas akun tertentu.

Untuk prosedur audit yang kurang dari 80\% dilakukannya, berikut hasil evaluasinya:

a. Untuk poin 5, prosedur mengecek umur piutang dari beberapa customer kurang banyak dilakukan karena tidak semua perusahaan klien membuat daftar umur piutang. Hal ini berdampak pada tidak terpenuhinya tujuan audit right, realizable value dan presentation \& disclosure Perusahaan klien yang tidak membuat daftar umur piutang merupakan risiko bawaan yang dapat menyebabkan terjadinya risiko audit dalam menentukan nilai salah saji yang terjadi dalam akun piutang usaha tersebut, baik dalam 
menilai hak atas nilai piutang usaha yang disajikan, atau dalam menilai piutang yang dapat direalisasikan, sehingga penyajian dan pengungkapannya dapat tidak sesuai dengan standar akuntansi yang berlaku umum di Indonesia, dalam hal ini SAK ETAP (Standar Akuntansi Keuangan untuk Entitas Tanpa Akuntabilitas Publik).

b. Untuk poin $6 \mathrm{c}$, prosedur mencantumkan nomor konfirmasi pada surat konfirmasi atau daftar piutang tidak dilakukan, hal ini menandakan kurang adanya pengendalian yang dilakukan oleh auditor. Prosedur ini tidak terlalu berdampak pada tingkat keyakinan atas salah saji dalam laporan keuangan. Namun harus tetap dilakukan auditor sebagai kontrol auditor atau dipakai sebagai pengendalian mutu audit.

c. Untuk poin 8, prosedur memeriksa wesel tagih tidak dapat dilakukan karena 21 perusahaan yang diambil sampel tersebut tidak mempunyai wesel tagih. Prosedur ini penting dilakukan untuk memenuhi tujuan existence, right dan presentation $\mathcal{E}^{\circ}$ disclosures.

d. Untuk poin 11, prosedur memeriksa notulen rapat / jawaban konfirmasi bank / correspondence file untuk melihat apakah ada piutang yang dijadikan sebagai jaminan, hal ini terlihat sama sekali dilakukan karena perusahaan klien yang dijadikan sampel tidak mempunyai piutang yang dijaminkan. Prosedur ini penting dilakukan untuk memenuhi tujuan existence dan presentation $\mathcal{E}^{\circ}$ disclosures.
Prosedur audit yang tidak dilakukan oleh auditor dapat tidak terpenuhinya tujuan audit, sehingga dapat berdampak pada berkurangnya tingkat keyakinan atas laporan keuangan. Namun dampak seberapa besar tingkat keyakinan ini berkurang tidak dikaji lebih lanjut. Dampak ini akan diteliti lebih lanjut pada penelitian selanjutnya.

\section{PENUTUP}

\section{Simpulan}

Berdasarkan hasil evaluasi atas prosedur audit yang dilakukan dapat disimpulkan bahwa masih terdapat auditor yang tidak sepenuhnya melakukan prosedur audit yang biasa dilakukan oleh KAP sehingga pemenuhan tujuan audit atas piutang usaha tidak dapat tercapat dengan baik. Tujuan audit yang banyak tidak terpenuhi adalah existence, right, dan presentation $\&$ disclosures, namun tidak diteliti mengenai dampak seberapa besar tingkat keyakinan ini terpengaruhi.

\section{Saran}

Untuk prosedur yang tidak dilakukan dan mempunyai dampak pada tidak tercapainya tujuan audit yang harus dipenuhi terhadap akun piutang usaha, auditor harus lebih fokus dan harus tetap menjalankan prosedur yang ada. Untuk penelitian selanjutnya disarankan untuk memperbesar jumlah sampel dan meneliti pengaruh tidak terpenuhinya tujuan audit terhadap tingkat keyakinan auditor atas laporan keuangan.

\section{Ucapan Terima Kasih}

Terima kasih kepada Program Vokasi Universitas Indonesia yang telah memberikan hibah sehingga terlaksananya penelitian ini dan pihak-pihak yang telah membantu dalam penelitian ini.

\section{DAFTAR PUSTAKA}

Agoes, Sukrisno. 2014. Auditing, Edisi Keempat, Buku 1. Penerbit Salemba Empat. Jakarta. 
2004. Auditing oleh Kantor Akuntan Publik, Edisi Ketiga, Jilid 1. Lembaga Penerbit Fakultas Ekonomi Universitas Indonesia. Jakarta.

ALMEIDA , Marcelo Cavalcanti. Audit: a modern, full course. São Paulo : Atlas , 2003

BOYNTON, William C. Audit. São Paulo : Atlas, 2002 .

Gil, Antonio Carlos . Methods and techniques of social research. São Paulo : Atlas , 1999

Guy, Dan M., C. Wayne Alderman, dan Alan J. Winters. 2002. AUDITING, Edisi Kelima, Jilid I, Erlangga, Yogyakarta.

Halim, Abdul 2008, Dasar-Dasar Audit Laporan Keuangan, UPP STIM YKPN, Yogyakarta.

IMONIANA, Joshua Onome. Auditing : a contemporary approach. São Paulo : Itapetininga Education Association, 2001. IMONIANA, Joshua Onome. Auditing : a contemporary approach . São Paulo : Itapetininga Education Association , 2001

Imoniana, Joshua Onome; et all. The Analytical Review Procedures in Audit: An Explarotory Study. Scientific \& Applied accounting. ISSN 1983-8611

Mulyadi. 2008. Sistem Akuntansi. Salemba Empat : Jakarta

NBC T 11. ACCOUNTING STANDARDS BRAZILIAN . NBC T 11 , of 17.12.1997

SANTI, Paulo Adolpho. Introdução à auditoria. São Paulo: Atlas, 1988.

SOUZA, Natólio de. Auditoria e gestão, aliança na evolução dos negócios. Gazeta Mercantil. São Paulo, Caderno D, p. 2, 23 ago. 1999..

WHEELER, Stephen; Kurt, PANY. Assessing the Performance of Analytical Procedures: A Best Case Scenario. The Accounting Review, v. 65, n. 3,p. 555-577, 1990.

Sumber Online :

https://asropi.wordpress.com/tag/eksploratif/ 